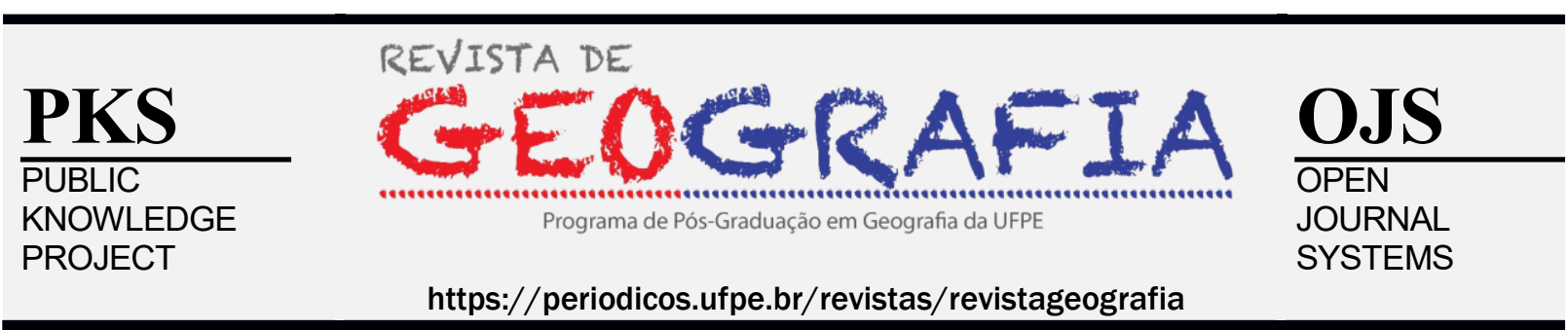

\title{
A NOVA GEOGRAFIA DAS BOLSAS DE MERCADORIAS E FUTUROS E A DINÂMICA DO CAPITAL FINANCEIRO NA AGRICULTURA
}

\author{
Marlon Clovis Medeiros ${ }^{1}$
}

${ }^{1}$ Universidade Estadual do Oeste do Paraná - UNIOESTE. Professor dos Cursos de Graduação e Pós-Graduação em Geografia da UNIOESTE- Francisco Beltrão Doutor em Geografia Humana pela Universidade de São PauloUSP Mestre em Geografia pela UNESP- Presidente Prudente Graduado em Geografia (Licenciatura) pela UDESC.E-mail: mcmedeiros@yahoo.com.br; ORCID iD:http://orcid.org/0000-0002-4648-6662

Artigo recebido em 30/03/2020 e aceito em 06/03/2021

\begin{abstract}
RESUMO
$\mathrm{O}$ artigo discute a dinâmica recente das bolsas de mercadorias e futuros, especialmente o crescimento das bolsas asiáticas e o mercado mundial de commodities agropecuárias. Exploramos os dados anuais dos relatórios da Future Industry Association-FIA, os quais permitem avaliar os principais indicadores de títulos, a dinâmica regional destes mercados e os processos de fusões e aquisições entre as bolsas. As bolsas asiáticas atingiram a liderança mundial, com mais de 39\% do total dos contratos de derivativos, futuros e opções. As bolsas norte-americanas e europeias vem seguindo o caminho das fusões e aquisições desde 2007. Das dez maiores bolsas, três são chinesas e uma é indiana. Na lista das maiores bolsas do ano de 2000, a única chinesa, aparecia em $32^{\circ}$ lugar, da Índia não constava nenhuma. Os dados demonstram a aceleração do crescimento econômico de China e Índia, e a desaceleração de Europa, Estados Unidos e Japão. Nos produtos agropecuários as bolsas da China lideram de forma absoluta, com $69,7 \%$ do total mundial de contratos desta categoria.
\end{abstract}

Palavras-chave: Derivativos agropecuários; Ásia; commodities agropecuárias; capital financeiro e agricultura.

\section{THE NEW GEOGRAPHY OF MERCHANDISE AND FUTURE STOCK EXCHANGES AND THE DYNAMICS OF FINANCIAL CAPITAL IN AGRICULTURETÍTULO EM INGLÊS}

\begin{abstract}
The article discusses the new dynamics of commodities and futures exchanges, especially the growth of the Asian stock exchanges and the world market for agricultural commodities. The annual data of the Future Industry Association-FIA reports are analyzed, which allow to evaluate the main indicators of securities, the regional dynamics of the markets and the processes of mergers and acquisitions between the exchanges. Asian stock markets have topped the global lead, with more than $39 \%$ of total futures and options contracts. US and European stock exchanges have been following the path of mergers and acquisitions since 2007. Of the 10 largest exchanges, three are Chinese and one is Indian. In the list of
\end{abstract}


the biggest exchanges of the year of 2000 , the only one Chinese, appeared in $32^{\circ}$ place, of India there were none. The data shows the acceleration of economic growth in China and India, and the slowdown in Europe, the United States and Japan. In agricultural products China's stock markets are the absolute leader with $69.7 \%$ of the world's total contracts.

Keywords: Agricultural derivatives; Asia; agricultural commodities; Financial capital and agribusiness

\section{INTRODUÇÃO}

O objetivo do presente artigo é discutir a dinâmica recente das bolsas de mercadorias e futuros, especialmente o imenso crescimento das bolsas asiáticas e o mercado de commodities agropecuárias. Exploramos os dados anuais dos relatórios da Futures Industry Association-FIA, os quais permitem avaliar os principais indicadores de títulos, a dinâmica geográfica destes mercados e os processos de fusões e aquisições entre as bolsas. O crescimento das bolsas foi intenso nos anos 2000, chamando atenção especialmente em 2008, com a aceleração dos preços de alimentos no mercado internacional. Abriu-se um grande debate em torno do papel da especulação em títulos de commodities agropecuárias no aumento dos preços de alimentos.

Nos anos recentes, diversos pesquisadores tem discutido o papel que o capital financeiro passou a ter na agricultura, e suas relações com os grandes grupos agroindustriais, a desnacionalização e concentração do capital no setor, como Benneti (2004) Gonçalves (2005 e 2012), Espíndola (2002 e 2014), Sampaio (2003), Correa (2012), Delgado (2012), Oliveira (2016) Medeiros (2014 e 2015), Balestro e Lourenço (2014), Santos (2012), entre outros. Internacionalmente também ampliou-se o debate sobre o tema, como Assouline, Joly e Lemarié (2001), Dicken (2010), Ziegler (2013), Wood (2013) entre muitos outros.

A imensa atuação que o capital financeiro vem apresentando no setor, nas últimas décadas, chamou a atenção para a dinâmica geral. Se tratava agora de analisar como a agricultura se inseria na acumulação dominada pelo capital financeiro, e não apenas pelo capital industrial, como nas décadas anteriores. ${ }^{1} \mathrm{O}$ debate agora é como a produção agropecuária é inserida na dinâmica do mercado de capitais sob a lógica própria do capital financeiro. Isto se tornou mais

\footnotetext{
${ }^{1} \mathrm{O}$ debate brasileiro em torno dos complexos agroindustriais enfatizava as ligações intersetoriais da indústria e da agroindústria com a agricultura, com domínio do capital industrial. Nesta dinâmica, o capital financeiro representava o papel de alavancar a acumulação industrial baseada na produção agropecuária. Ou seja, o elemento considerado dominante era o capital industrial.
} 
explícito após a grande inflação de alimentos no mercado mundial ocorrida em 2008, à qual se seguiram inúmeros debates internacionais.

As bolsas de mercadorias e futuros se tornaram um dos elementos mais importantes desta dinâmica, pois ao mesmo tempo se tornaram fonte de recursos para as grandes tradings agropecuárias, local privilegiado de investimento para especuladores e fundos, e reguladoras dos preços internacionais de commodities agrícolas. O crescimento total do número de contratos agropecuários negociados nas bolsas, no período 2000-2015, foi de 1.196\%, muito acima do crescimento das exportações de commodities agropecuárias.

O referencial teórico principal vem da análise da expansão internacional da acumulação do capital baseado em Marx (1982) e Lenin (2011). ${ }^{2}$ Este movimento aprofunda a dinâmica do capitalismo monopolista tal como apontada um século atrás por Lenin (2011), de que progressivamente o mercado de capitais se torna mais importante do que a produção real e passa a comandá-la.

\section{AS BOLSAS DE MERCADORIAS E O CAPITAL FINANCEIRO NA AGRICULTURA}

A última década do século XX e a primeira do século XXI viram o papel do capital financeiro avançar sobre a agricultura de forma muito mais intensa do que imaginavam os analistas. Sob o capital financeiro, o mercado de capitais torna-se mais importante que o de mercadorias, e a antecipação dos investimentos à produção real se aprofunda. As bolsas de mercadorias e futuros são centrais nesta dinâmica, pois ao mesmo tempo se tornaram fonte de recursos para as grandes tradings agropecuárias, local privilegiado de investimento para especuladores e fundos, e reguladoras dos preços internacionais de commodities agrícolas, como indicaram, entre outros, Gonçalves (2005 e 2012) e Ziegler (2013).

Este movimento se relaciona à dinâmica do capitalismo monopolista apontada por Lenin (2011), na qual o mercado de capitais se torna protagonista do desenvolvimento dos setores produtivos, passando a comandá-los.

Até mesmo nas relações regionais houve grande avanço do capital, o qual vem demonstrando profunda capacidade de adaptação às particularidades, políticas e culturais. Os grandes grupos

\footnotetext{
${ }^{2}$ Original de 1917.
} 
internacionais do agronegócio possuem numeroso corpo de pessoal de pesquisa, de vendas, de marketing, entre outros, dedicados a ampliar as redes de relações de suas empresas. As estratégias territoriais de expansão da influência pelos grandes grupos agroindustriais são inúmeras: fornecimento de assistência técnica, realização de seminários e encontros com os produtores, patrocínio a eventos locais, cursos para lideranças, acordos comerciais e financeiros com cooperativas agropecuárias, criação de campos experimentais em inúmeras regiões, financiamento direto do custeio para grandes produtores, construção de unidades de armazenagem em todas as regiões agrícolas, entre outras.

A dinâmica financeira se tornou tão abrangente, que mesmo para além dos grupos monopolistas, as próprias cooperativas de produtores agrícolas se direcionaram para o crédito e para a intermediação de vendas antecipadas e de títulos financeiros ${ }^{3}$.

As bolsas de mercadorias e futuros passaram a ocupar papel central na expansão internacional do capital financeiro sobre as atividades agropecuárias no início do século XXI. O desenvolvimento do mercado de títulos de commodities agropecuárias, especialmente o mercado de futuros, trouxe uma das principais características do capital financeiro para o agro:

a antecipação dos investimentos à ocorrência da produção real. O movimento dos investimentos em títulos ocorre antes das safras, levando a que os preços futuros variem não mais em função das safras, mas em função da expectativa dos investidores sobre as safras (MEDEIROS, 2015).

A possibilidade de investidores de fora do setor agropecuário atuarem nas commodities agropecuárias, aprofundou esta dinâmica, pois levou ao setor inúmeros agentes interessados unicamente no ganho com a variação dos valores dos títulos. Após várias crises financeiras na década de 1990, e especialmente a crise das empresas de internet em 1999, os grandes investidores buscam outras alternativas mais seguras, migrando em massa para as commodities "reais".

\footnotetext{
${ }^{3}$ As cooperativas agropecuárias possuem amplo papel no processo de financeirização da agricultura brasileira. Primeiramente na fase inicial de implantação do Sistema Nacional de Crédito Rural- SNCR atuaram organizando e estimulando os produtores à utilização do crédito. Com a crise do crédito na década de 1990, as cooperativas passaram a financiar diretamente os produtores e pressioná-los por melhores rendimentos e produtividade. A crise levou à concentração de capital nas maiores cooperativas e ao maior aperto das exigências sobre os produtores.
} 
Nos anos 1990 os grandes investidores institucionais se tornam centrais, especialmente os fundos mútuos (que gerenciam as grandes fortunas familiares) e os fundos de pensão (SAUVIAT, 2005).

A desregulamentação financeira promovida pelos Estados Unidos no governo Clinton impulsionou o mercado de derivativos e a engenharia financeira como apontou Stiglitz (2010):

Esses derivativos estão entre as inovações de que os participantes do mercado financeiro têm mais orgulho. O nome diz bastante a respeito da sua essência: o seu valor é derivado de um outro ativo. A aposta de que o preço de uma ação estará mais alto no dia seguinte é um derivativo. A aposta de que o valor de mercado de uma aposta estará mais alto no dia seguinte é um derivativo baseado em um derivativo. O número de produtos que podem ser inventados dessa maneira é infinito. Os derivativos são uma faca de dois gumes. Por um lado, podem ser usados para administrar os riscos. [...] Por outro lado, como assinalou Warren Buffett, os derivativos também podem ser armas financeiras de destruição em massa. (STIGLITZ, 2010, p. 162).

$\mathrm{Na}$ esteira das liberalizações financeiras em diversos países e do desenvolvimento dos derivativos, os Estados Unidos ampliam significativamente o envio e o recebimento de investimentos estrangeiros diretos, com forte impacto nas bolsas.

No âmbito da agricultura, Balestro e Lourenço (2014) discutem o impacto da expansão dos derivativos:

Com os limites estruturais impostos ao crescimento da produção e do consumo (seja por questões ambientais ou questões de mercado), há uma fuga pelo uso crescente de derivativos nos sistemas agroalimentares em que o foco no desempenho no mercado financeiro se tornou mais importante do que o no mercado real. Desprovidos de um limite físico, os derivativos de commodities chegam a superar em 20 a 30 vezes a produção física das commodities. (BALESTRO e LOURENÇO, 2014, p. 251).

O estudo também aponta o distanciamento entre os investimentos em títulos agropecuários e a produção real na agricultura:

Tais produtos são considerados investimentos financeiros que fornecem uma oportunidade de diversificar o portfólio financeiro sem a necessidade de uma compra física, uma vez que o importante é gerar liquidez. Não apenas os bancos, mas também as grandes tradings de commodities se envolveram fortemente no mercado de derivativos agrícolas, como foi o caso das norteamericanas ADM, Bunge e Cargill e da francesa Louis Dreyfus. Os fundos de 
pensão também se constituíram em atores importantes em âmbito internacional. [...]

(BALESTRO e LOURENÇO, 2014, p. 252)

Assim, o mercado de derivativos, especialmente via bolsas de mercadorias e futuros, deixou de ser apenas uma fonte de financiamento para produtores e indústria ou um local para se fazer hedge (securitização) contra variações futuras de preços, se tornando um local central de aplicação de capital em valorização de títulos financeiros. Um dos elementos que ampliou a liquidez do mercado de títulos agropecuários foi a possibilidade de liquidação financeira dos contratos, ao passo que anteriormente somente se encerrava um contrato com a entrega física do produto agropecuário. No Brasil isto foi possível a partir de 2001.

\section{O CRESCIMENTO RECENTE DAS BOLSAS DE MERCADORIAS E DE FUTUROS}

No início do século XXI ocorreu uma aceleração da movimentação das bolsas de mercadorias e futuros em todo o mundo. Estas acabam por assumir um papel central na dinâmica financeira internacional, tanto para as commodities (minerais, energéticas e agropecuárias), quanto para as moedas nacionais.

No mesmo período, a China amplia significativamente sua produção industrial, e ao adentrar na OMC em 2001 acelera suas exportações. Neste movimento, as bolsas de mercadorias da China ampliam significativamente suas compras no mercado internacional, especialmente de commodities utilizadas pela indústria do país, como borracha, soja, minério de ferro, aço, petróleo, entre outros. Este movimento é um dos principais que impulsiona as bolsas de mercadorias e futuros de todo o mundo a um crescimento acelerado.

Como demonstrou Medeiros (2006), a crise asiática de 1997 foi um divisor de água na atuação no mercado internacional, pois tanto as exportações quanto as importações chinesas crescem vertiginosamente a partir de então.

Após abrupta recessão e colapso cambial (desvalorizações de cerca de 50\% em relação ao dólar) ocorrida em 1997, as economias da ASEAN ao lado da Coréia, com exceção da Indonésia, retomaram suas trajetórias expansivas a partir de uma política fiscal expansiva e forte recuperação das suas exportações. O fator imediato responsável pelo crescimento das exportações foi o boom da "nova economia" nos EUA e seu impacto na Tecnologia de Informação (TI); com o estouro da bolha ocorrida em 2000/2001, as 
exportações asiáticas se expandiram em função do alto crescimento da China. Mantendo inalterada sua taxa nominal de câmbio com o dólar, a China reagiu à contração de suas exportações com uma política anticíclica centrada nos investimentos públicos. [...] Graças à manutenção de um extraordinário crescimento econômico e da estabilidade do yuan a China, que se afirmou como um exportador líquido para os EUA e o Japão, transformou-se, simultaneamente, num importador líquido para a Ásia. (MEDEIROS, 2006, p. 382 e 383$)$.

Embora tenha havido oscilações negativas em determinados anos, de maneira geral as bolsas de mercadorias e futuros cresceram intensamente ao longo dos anos 2000. No gráfico 1 podese observar o volume total mundial de contratos de futuros e opções. Partindo de 2,9 bilhões de contratos em 2000, e chegando em 2015 a 24,7 bilhões. Isto marca um crescimento médio anual de $50 \%$, e um crescimento total de $751 \%$. Mesmo com a crise de 2008 , houve crescimento no ano de 2009, devido ao desempenho das bolsas da Ásia e da América Latina. Nas bolsas da Europa e da América do Norte houve forte queda no ano de 2009. Houve queda no número mundial de contratos apenas do ano de 2011 para 2012, mas ainda assim, permanecendo em volumes muito superiores aos início da década.

No gráfico 1 pode-se observar o volume total mundial de contratos de futuros e opções.

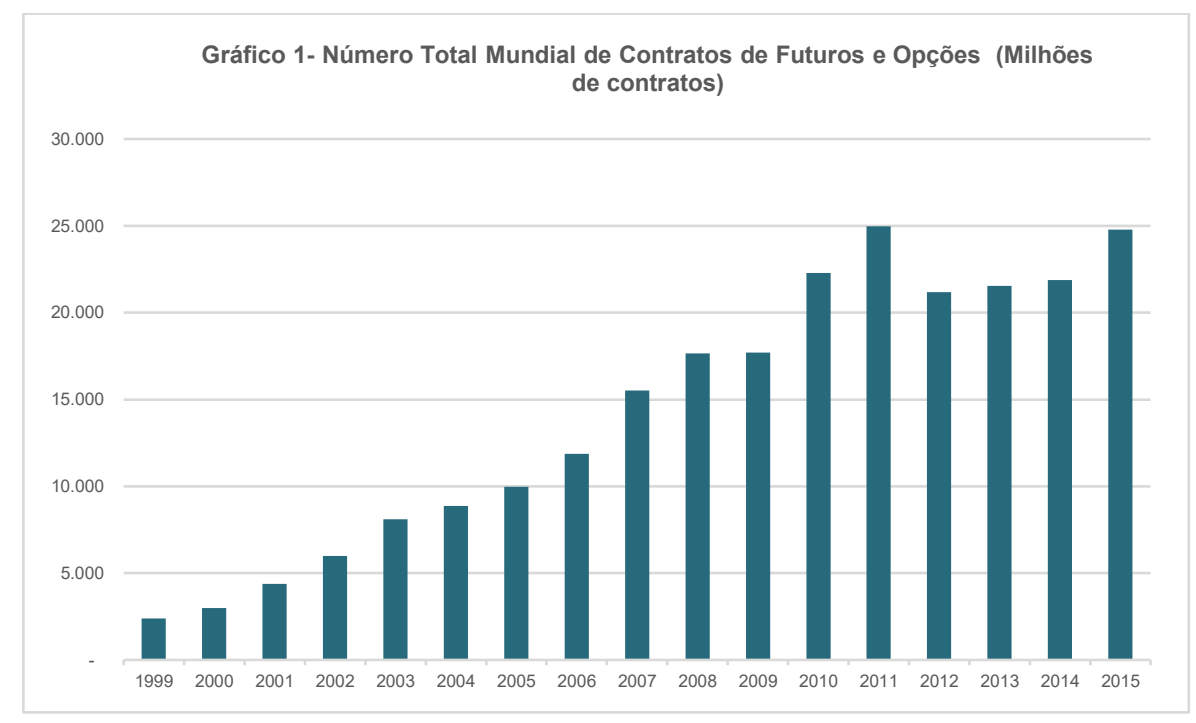

Fonte: Futures Industry Association. Annual Volume Survey. Diversos Anos.

O número de contratos por categorias também demonstra crescimento contínuo e intenso. Os futuros e opções financeiros representam o maior volume (índice de ações, ações individuais, taxas de juros e moedas), mas o crescimento das commodities foi intenso. No ano 2000 os 
contratos financeiros representavam $84,7 \%$ do total, passando para 85,5\% em 2010 e caindo para 77,8\% em 2015. Já as commodities agropecuárias representavam apenas 1,5\% do total em 2000, crescendo para 5,8\% em 2010, e 6,6\% em 2015.

Os dados demonstram que as commodities (incluindo agropecuárias, energéticas e metálicas) avançaram proporcionalmente mais que os futuros financeiros, partindo de 15,04\% em 2000, para 18,6\% em 2015. Pode parecer um avanço pequeno na participação total, mas está se considerando um universo de 24,7 bilhões de contratos, em 2015, que no ano 2000 eram de 2,3 bilhões.

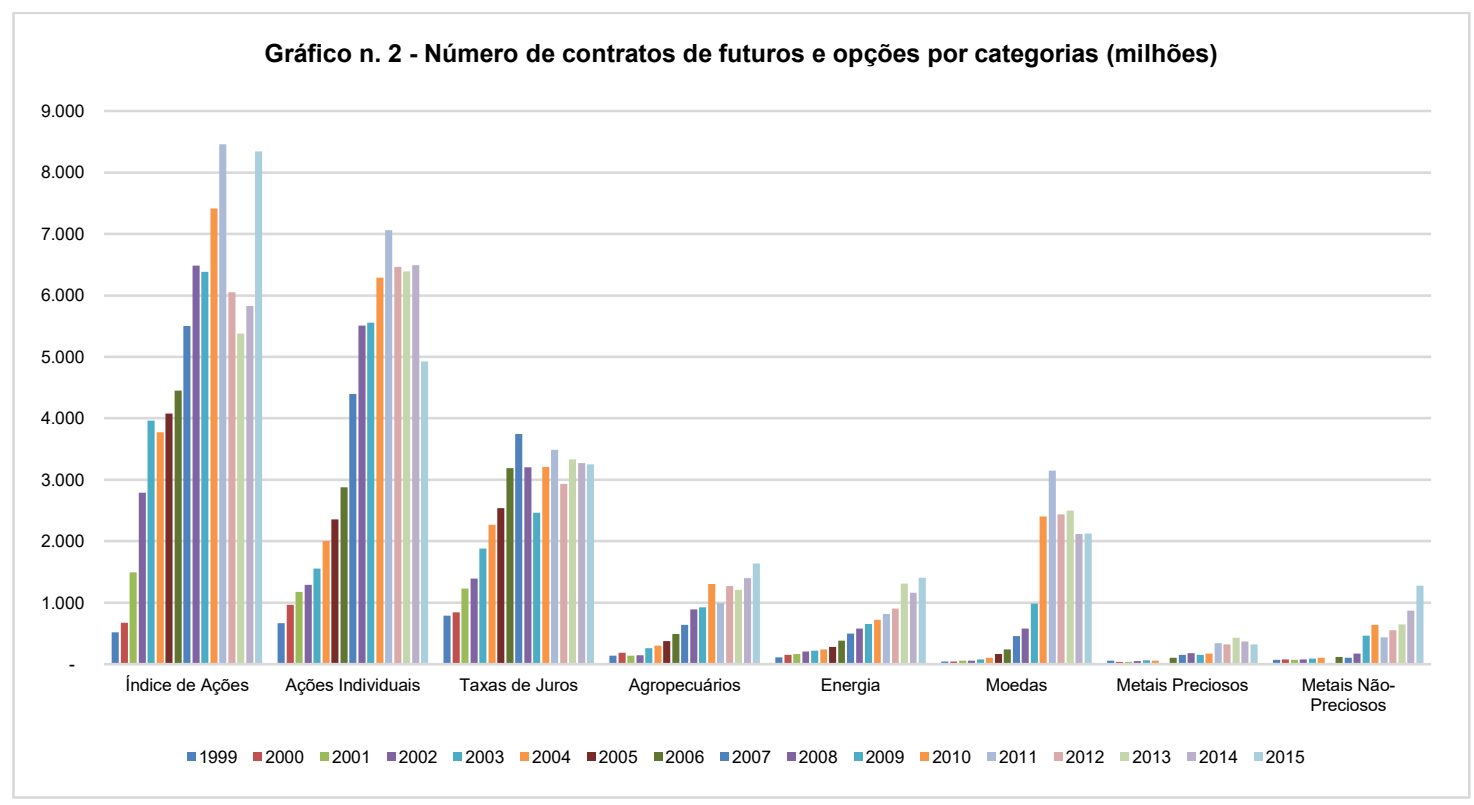

Fonte: Futures Industry Association. Annual Volume Survey. Diversos Anos.

O crescimento total do número de contratos agropecuários no período 2000-2015 foi de $1.196 \%$, enquanto o de commodities energéticas foi de $1.268 \%$ e o de minerais foi de $1.829 \%$. Para compreendermos como este movimento foi dinâmico, o crescimento das exportações mundiais no mesmo período foi de $156 \%$, o de investimentos estrangeiros totais $30,4 \%$, e o PIB mundial total $122,6 \%$. O PIB Chinês, no mesmo período cresceu $824,1 \%$, enquanto as exportações da China cresceram $812 \%$, e as importações $646 \%{ }^{4}$.

\footnotetext{
4 Dados de UNCTADstat. Economic $\quad$ Trends. Disponível em https://unctadstat.unctad.org/wds/ReportFolders/reportFolders.aspx para os dados de comércio mundial, IED e PIB.
} 


\section{O LESTE ASIÁTICO E AS BOLSAS DE MERCADORIAS}

Nos anos 2000 o Leste Asiático permaneceu na liderança do crescimento econômico mundial, e na posição de principal região industrial. Mesmo com a crise do Japão desde início dos anos 1990, que liderava economicamente a região, e com a crise asiática de 1997, o Leste asiático continuou crescendo fortemente. A China assumiu um protagonismo econômico, ao passo que Coreia do Sul, Taiwan e Cingapura permanecem crescendo aceleradamente (MEDEIROS, 2006; JABBOUR, 2010). Os países do Leste Asiático levaram adiante um processo de desenvolvimento industrial com forte papel do Estado (ARRIGHI, 1994, 2008; AMSDEN, 2009). No mesmo período a Índia inicia um período de elevado crescimento econômico e amplia sua participação na economia mundial.

Com isto, o Leste Asiático passa a disputar o mercado internacional de fornecimento de commodities e de investimentos, impulsionando tanto as bolsas de valores quanto as bolsas de mercadorias e futuros. Em 2015 as bolsas asiáticas atingiram a liderança mundial, com mais de $39 \%$ do total dos contratos de derivativos, futuros e opções, ao passo que as bolsas dos Estados Unidos e da Europa praticamente não cresceram desde 2010, como se observa no gráfico 3.

As bolsas norte-americanas e europeias, em reação, seguiram o caminho das fusões e aquisições desde 2007 (PASSOS, 2007). Como se observa no gráfico 3, as bolsas dos Estados Unidos e da Europa praticamente não cresceram desde 2010. A dinâmica de fusões e aquisições, já utilizada há décadas nos mais variados setores produtivos, chegou às bolsas de valores e de mercadorias e futuros. Isto acentuou a concentração de capital no mais alto nível do capital financeiro, já muito concentrado. 


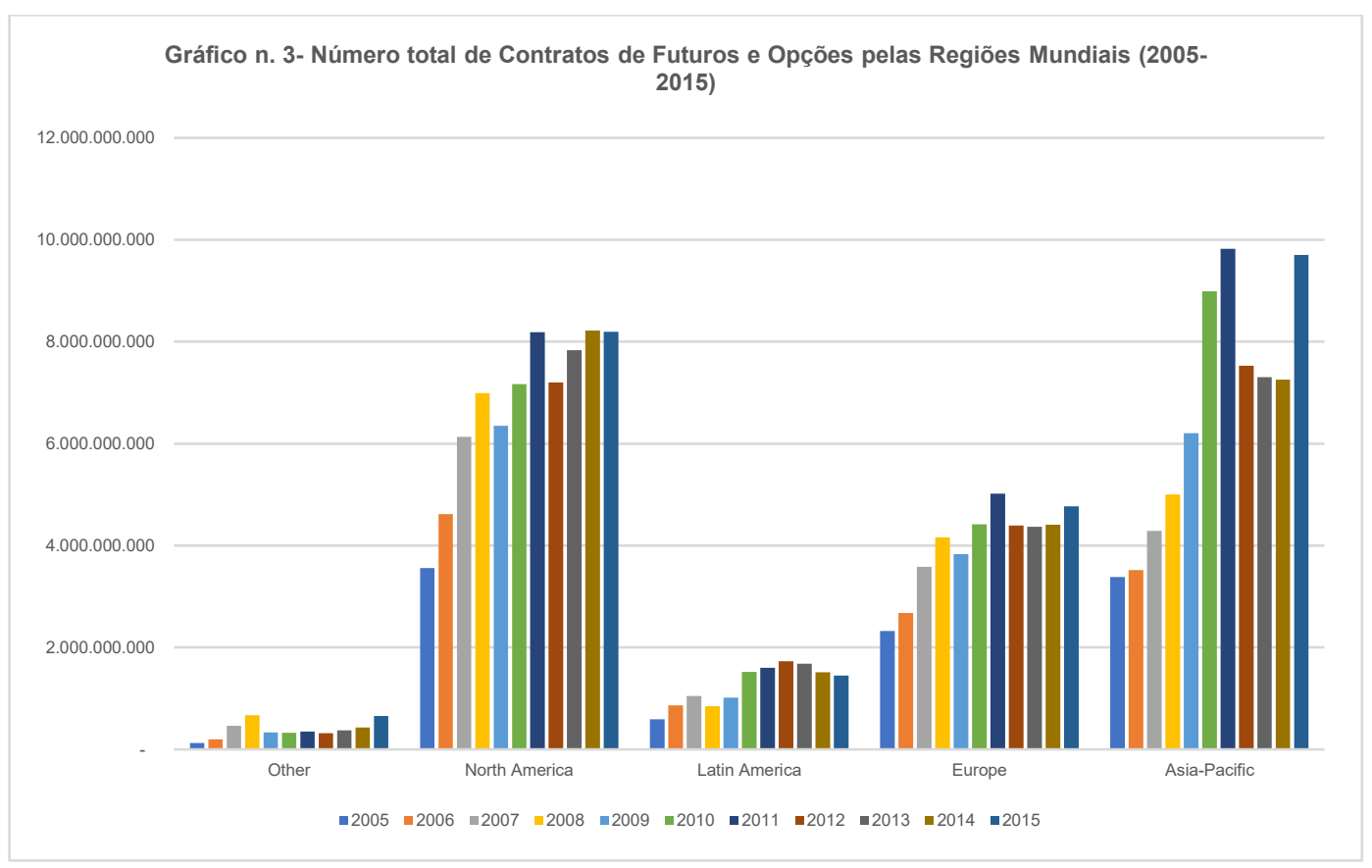

Fonte: Futures Industry Association. Annual Volume Survey. Diversos Anos.

Nos anos de 2014 e 2015 a National Stock Exchange of India cresceu 61,2\%, se tornando a segunda mundial, superando as gigantes Eurex e Intercontinental Exchange, ambas originárias de megafusões. A BM\&FBovespa, também originária de fusão, era a sexta maior em 2015, mas concentrada em futuros financeiros.

Das dez maiores bolsas, três são chinesas e uma é indiana. Até início dos anos 2000, as bolsas da Coreia do Sul, do Japão e de Cingapura figuravam entre as maiores. Na lista das maiores bolsas do ano de 2000, a única chinesa, a Shangai Futures Exchange, aparecia em $32^{\circ}$ lugar, ao passo que da Índia não constava nenhuma.

Os dados demonstram a aceleração do crescimento econômico de China e Índia, e a desaceleração de Europa, Estados Unidos e Japão. Nos produtos agropecuários as bolsas da China lideram de forma absoluta em movimentação. A Bolsa de Commodities de Dalian, a Bolsa de Commodities de Zhenzou e a Bolsa de Futuros de Shangai movimentaram 1,1 bilhão de contratos de óleo, farelo e grão de soja, óleo de palma refinado, milho, amido de milho, ovos, canola, açúcar branco, borracha e algodão. As três bolsas juntas movimentaram $69,7 \%$ do total mundial de contratos de commodities agropecuárias. Este valor é muito representativo, visto que tradicional Bolsa de Chicago movimentou 282,9 milhões de contratos de milho, soja, trigo 
vermelho, óleo de soja e farelo de soja ${ }^{5}$. A concentração da movimentação nas bolsas se acentua nos anos mais recentes, como pode-se observar no quadro número 01. As cinco maiores bolsas concentraram em $201954,7 \%$ do total dos contratos mundiais. Ampliando a análise para as 20 maiores bolsas, esse percentual chega a $95,6 \%{ }^{6}$.

\begin{tabular}{|c|c|c|c|c|}
\hline RANKING & Bolsa & $\begin{array}{l}\text { Número de } \\
\text { contratos }\end{array}$ & $\begin{array}{c}\text { Cresc. } \\
\text { 2019-2018 }\end{array}$ & Part. \% \\
\hline 1 & National Stock Exchange of India & 5.960 .653 .879 & $57,27 \%$ & 17,3 \\
\hline 2 & CME Group & 4.830 .045 .369 & $-0,31 \%$ & 14,0 \\
\hline 3 & B3 & 3.880 .624 .283 & $50,76 \%$ & 11,3 \\
\hline 4 & Intercontinental Exchange & 2.256 .762 .531 & $-8,79 \%$ & 6,5 \\
\hline 5 & Eurex & 1.947.144.196 & $-0,24 \%$ & 5,6 \\
\hline 6 & CBOE Holdings & 1.912.075.382 & $-6,77 \%$ & 5,5 \\
\hline 7 & Nasdaq & 1.785 .341 .204 & $-5,77 \%$ & 5,2 \\
\hline 8 & Korea Exchange & 1.546.717.194 & $9,83 \%$ & 4,5 \\
\hline 9 & Moscow Exchange & 1.455 .043 .932 & $-3,02 \%$ & 4,2 \\
\hline 10 & Shanghai Futures Exchange & 1.447.597.054 & $20,44 \%$ & 4,2 \\
\hline 11 & Dalian Commodity Exchange & 1.355 .584 .225 & $38,05 \%$ & 3,9 \\
\hline 12 & Zhengzhou Commodity Exchange & 1.092 .703 .580 & $33,59 \%$ & 3,2 \\
\hline 13 & BSE & 1.026 .425 .811 & $-0,61 \%$ & 3,0 \\
\hline 14 & Miami International Holdings ${ }^{1}$ & 440.049 .131 & $4,45 \%$ & 1,3 \\
\hline 15 & Hong Kong Exchanges and Clearing & 438.690 .021 & $-8,79 \%$ & 1,3 \\
\hline 16 & Borsa Istanbul & 387.996 .034 & $64,13 \%$ & 1,1 \\
\hline 17 & Japan Exchange Group & 361.063 .321 & $-12,35 \%$ & 1,0 \\
\hline 18 & Multi Commodity Exchange of India & 306.592 .744 & $33,10 \%$ & 0,9 \\
\hline 19 & Taiwan Futures Exchange & 260.765 .482 & $-15,36 \%$ & 0,8 \\
\hline 20 & ASX & 260.478 .736 & $5,03 \%$ & 0,8 \\
\hline
\end{tabular}

\footnotetext{
${ }^{5}$ Futures Industry Association. Annual Volume Survey. Diversos Anos.

${ }^{6}$ Futures Industry Association. Annual Volume Survey. 2019.
} 
É necessário enfatizar que em todo o período analisado, o maior crescimento foi das bolsas da Ásia, pois as principais bolsas do Brasil, dos Estados Unidos e da Europa permanecem entre as maiores devido a grandes processos de fusões ocorridos entre 29 bolsas que originaram 6 grandes bolsas. Estas são as seguintes: CME Group, Intercontinental Exchange, Eurex, B3, CBOE Holdings e Nasdaq. A segunda maior bolsa por exemplo, o CME Group é resultado das fusões de 4 bolsas: Chicago Mercantile Exchange, Chicago Board of Trade, New York Mercantile Exchange e Commodity Exchange (COMEX). A terceira maior bolsa, a brasileira B3, originou-se da fusão da Bovespa, BM\&F e Cetip. Já o grupo Intercontinental Exchange originou-se da fusão de: ICE Futures Europe, NYSE Arca, NYSE Amex, ICE Futures US e ICE Futures Singapore ${ }^{7}$.

Tabela 02- Participação \% das Regiões no Total de Contratos de Futuros e Opções Mundiais

\begin{tabular}{l|lllll}
\hline ANOS & ÁSIA & $\begin{array}{l}\text { AMÉRICA } \\
\text { NORTE }\end{array}$ & DO EUROPA & $\begin{array}{l}\text { AMÉRICA } \\
\text { LATINA }\end{array}$ & OUTRAS \\
\hline $\mathbf{2 0 1 0}$ & 40,1 & 32 & 20 & 7 & 1 \\
$\mathbf{2 0 1 1}$ & 39,4 & 33 & 20 & 6 & 1 \\
$\mathbf{2 0 1 2}$ & 35,6 & 34 & 21 & 8 & 1 \\
$\mathbf{2 0 1 3}$ & 33,9 & 36 & 20 & 8 & 2 \\
$\mathbf{2 0 1 4}$ & 33,2 & 38 & 20 & 7 & 2 \\
$\mathbf{2 0 1 5}$ & 39,1 & 33 & 19 & 6 & 3 \\
$\mathbf{2 0 1 6}$ & 36,4 & 34 & 21 & 6 & 3 \\
$\mathbf{2 0 1 7}$ & 35,0 & 35 & 20 & 8 & 2 \\
$\mathbf{2 0 1 8}$ & 37,0 & 35 & 17 & 9 & 2 \\
$\mathbf{2 0 1 9}$ & 42,0 & 30 & 15 & 12 & 2 \\
\hline & & Fonte: Futures Industry Association. Annual Volume Survey, 2019. &
\end{tabular}

É importante ressaltar que mesmo que a maior bolsa chinesa seja apenas a décima maior, a Bolsa de Futuros de Shangai, o conjunto das bolsas chinesas e asiáticas representou o maior volume de contratos, com $42 \%$ do total. Este resultado vem crescendo desde 2015 como se observa na tabela 02 . O mercado de futuros e derivativos na China ainda é exercido quase totalmente pelos próprios grupos chineses, uma vez que apenas a partir de 2017,

\footnotetext{
${ }^{7}$ Futures Industry Association. Annual Volume Survey. 2019.
} 
progressivamente se permitiu a participação de estrangeiros. O setor é fortemente controlado pela Comissão de Regulação de Valores Mobiliários da China.

Os dados demonstram uma mudança significativa na geografia das finanças internacionais, no que tange à bolsas de mercadorias e futuros. De 2010 a 2014 houve queda na participação das bolsas asiáticas, estabilidade na participação das europeias e leve crescimento das bolsas da América do Norte. De 2015 em diante houve crescimento acelerado das bolsas asiáticas e queda na participação das bolsas da Europa e América do Norte.

Estas se tornaram centrais no financiamento da produção agropecuária e na movimentação de safras. As bolsas da Europa e dos Estados Unidos perderam espaço especialmente após a crise de 2008, enquanto as bolsas da China e da Índia, que já cresciam intensamente, aceleram sua participação nos totais mundiais. As bolsas indianas atuam especialmente em futuros financeiros.

As bolsas chinesas se tornaram centrais na oscilação dos preços internacionais de commodities agropecuárias e metálicas. As bolsas de mercadorias se tornaram fundamentais para o abastecimento da indústria chinesa de matérias-primas, bem como para a proteção contra as oscilações de preços internacionais e contra os movimentos especulativos de títulos.

\section{Conclusões}

$\mathrm{O}$ avanço da agricultura moderna e do capital monopolista desde o século XX ampliou sobremaneira a dinâmica financeira das atividades agropecuárias e agroindustriais. $\mathrm{O}$ desenvolvimento do sistema financeiro paulatinamente criou inúmeras formas de relação com as atividades agropecuárias e abrangem: financiamentos, títulos secundários das dívidas, seguros, derivativos agropecuários, ações de empresas, entre outros. A expansão desta dinâmica tornou a propriedade da terra secundária no direcionamento da agricultura, pois a capacidade financeira permite a realização de arrendamentos e parcerias ao invés da imobilização de capital em terra.

Ocorre rápido crescimento da influência do capital financeiro na agricultura mundial a partir da década de 1990, por um lado pela imensa centralização do capital em torno dos grupos produtores de insumos-equipamentos-defensivos-produtos agrícolas na forma de grandes 
conglomerados industriais-financeiros internacionais, E por outro pelo crescimento do papel das bolsas de mercadorias e futuros no financiamento da produção e da exportação de produtos agrícolas. Isto foi fruto inicialmente da pressão dos países desenvolvidos sobre os demais países para que estes abrissem seus mercados, para ampliar a dinâmica de exportação de capitais.

Como resultado, a dinâmica financeira se tornou o elo de ligação entre as cadeias produtivas mundiais de produtos agrícolas, desde a produção primária, à produção de equipamentos e insumos, à circulação de produção e a abertura de novos campos de investimentos via bolsas de mercadorias e futuros. Assim o elemento financeiro se apropriou da dinâmica agrícola, impondo sua própria lógica. A própria oscilação de safras e de preços agrícolas passa a ser determinada pela expectativa dos investimentos financeiros nos papéis agropecuários.

Com o estouro das bolhas financeiras na década de 1990 ocorreu migração de grande volume de capital para aplicações em commodities tradicionais, especialmente as energéticas e as agrícolas, que oferecem mais estabilidade. Ao lado disto, o crescimento chinês estimulou o mercado mundial destas commodities. As bolsas asiáticas atingiram a liderança mundial, com mais de $39 \%$ do total dos contratos de derivativos, futuros e opções em 2015. Nos anos seguintes permanecem crescendo atingindo 42\% do total mundial em 2019.

As bolsas norte-americanas e europeias vem seguindo o caminho das fusões e aquisições desde 2007. Das dez maiores bolsas, três são chinesas e uma é indiana. Na lista das maiores bolsas do ano de 2000, a única chinesa, aparecia em $32^{\circ}$ lugar, da Índia não constava nenhuma. Os dados demonstram a aceleração do crescimento econômico de China e Índia, e a desaceleração de Europa, Estados Unidos e Japão. Nos produtos agropecuários as bolsas da China lideram de forma absoluta, com $69,7 \%$ do total mundial de contratos desta categoria.

\section{REFERÊNCIAS}

AMSDEN, Alice H. A Ascensão do Resto: os desafios ao ocidente de economias com industrialização tardia. São Paulo: Editora da Unesp, 2009.

ARRIGHI, Giovanni. O Longo Século XX. Rio de Janeiro: Contraponto/EDUNESP, 1994. ARRIGHI, Giovanni. Adam Smith em Pequim: Origens e Fundamentos do Século XXI. São Paulo: Boitempo, 2008. 
ASSOULINE, Gérald, JOLY, Pierre-Benoit, LEMARIÉ, Stephanie. Biotecnologias vegetais e reestruturações do setor de provisões agrícolas: um horizonte estratégico marcado por fortes incertezas. In: Ensaios FEE, Porto Alegre, v.22, n. 02, 2001.

BALESTRO, Moisés V. LOURENÇO, Luiz C. B. Notas para uma análise da financeirização do agronegócio Além da volatilidade dos preços das commodities. In: BUAINAIN, Antônio M. ALVES, Eliseu et all (org.). O mundo rural no Brasil do século 21: a formação de um novo padrão agrário e agrícola. Brasília, DF : Embrapa, 2014.

BENETTI, Maria Domingues. Globalização e Desnacionalização do Agronegócio Brasileiro no Pós-1990. Documentos FEE, n 61. Porto Alegre: FEE, 2004.

DICKEN, P. Mudança Global: mapeando as novas fronteiras da economia mundial. Porto Alegre: Bookman, 2010.

ESPINDOLA Carlos J. A internacionalização do agronegócio brasileiro de carnes: a trajetória da Brasil Foods. In: Congresso iberoamericano de estudos territoriais e ambientais, 6, 2014, São Paulo, v. 01. p. 1866-1882.

ESPINDOLA, C. J. As agroindústrias de carne do sul do Brasil. 2002. 268 f. Tese (Doutorado) - Curso de Geografia, Faculdade de Filosofia, Letras e Ciências Humanas, Universidade de São Paulo, São Paulo, 2002.

GONÇALVES, José Sidnei. Agricultura Sob A Égide Do Capital Financeiro: Passo Rumo Ao Aprofundamento Do Desenvolvimento Dos Agronegócios. In: Informações Econômicas, SP, v.35, n.4, abr. 2005.

GONÇALVES, José Sidnei. Do Bonde ao Trem-bala: o fim do domínio da genética pública e o novo padrão de financiamento do custeio agropecuário. Análise e Indicadores do Agronegócio, v. 7, n. 4, abril 2012.

JABBOUR, Elias. Projeto Nacional, Desenvolvimento e Socialismo de Mercado na China Hoje. São Paulo: FFLCH/USP, 2010. (Tese de Doutorado em Geografia Humana).

LENIN, Vladimir Ilitch. Imperialismo: Fase Superior do Capitalismo. Campinas: Unicamp, 2011.

MAMIGONIAN, Armen. A Geografia e a Formação Social como Teoria e como Método. In: SOUZA, Maria Adélia Aparecida de (Org.). O Mundo do Cidadão, Um Cidadão do Mundo. São Paulo: Hucitec, 1996.

MARX, Karl. O Capital, livro 1 vol. I e II. São Paulo: Abril Cultural, 1984. 
MEDEIROS, Carlos A. A China como um duplo pólo na economia mundial e a recentralização da economia asiática in: Revista de Economia Política, vol. 26, nº 3 (103), pp. 381-400 julhosetembro/2006 pp. 381-400.

MEDEIROS, Marlon, C. Capital financeiro e o mercado mundial de produtos agrícolas. In: ESPÍNDOLA, Carlos J, MARTINS, César A. Brasil: Temas de Geografia Econômica. Rio Grande: Ed. Da FURG, 2015.

MEDEIROS, Marlon C. A geografia do mercado mundial de produtos agroalimentares e o papel do Brasil. Ra'e Ga - Curitiba, v.31, p.260-279, Ago/2014

OLIVEIRA, Ariovaldo U. A Mundialização da agricultura brasileira. São Paulo: Iãnde, 2016.

PASSOS, Maria H. Bolsas Mundiais Abrem-se as bolsas em todo o mundo. In: Revista Bovespa, out-dez, 2007.

RANGEL, Ignácio. Obras Reunidas. Vol 1 e 2. Rio de Janeiro: Contraponto/BNDES, 2005. SAMPAIO, Fernando dos Santos. Made in Brazil: Dinâmica sócio-espacial da indústria citrícola paulista. São Paulo: FFLCH/USP, 2003. (Tese de Doutorado em Geografia Humana). SANTOS, Leandro B. Estado, industrialização e o espaço da acumulação das multilatinas. Presidente Prudente: UNESP/FCT, 2012 (Tese de Doutorado em Geografia).

SAUVIAT, Catherine. Os Fundos de Pensão e os Fundos Mútuos: Principais atores da finança mundializada. In: CHESNAIS, François. A Finança Mundializada. São Paulo: Boitempo, 2005.

STIGLITZ, J. E. O Mundo em queda livre: os Estados Unidos e o mercado livre e o naufrágio da economia mundial. São Paulo: Cia. das Letras, 2010.

ZIEGLER, Jean. Destruição em Massa. Geopolítica da Fome. São Paulo: Cortez, 2013. 